\title{
Classifiers and DP
}

Cheng, L.L.; Sybesma, R.P.E.

\section{Citation}

Cheng, L. L., \& Sybesma, R. P. E. (2012). Classifiers and DP. Linguistic Inquiry, 43(4), 634-650. doi:10.1162/ling_a_00109

Version: Publisher's Version

License: $\quad$ Licensed under Article 25fa Copyright Act/Law (Amendment Taverne)

Downloaded from: $\quad$ https://hdl.handle.net/1887/3245538

Note: To cite this publication please use the final published version (if applicable). 


\title{
Classifiers and DP
}

\author{
Lisa Lai-Shen Cheng \\ Rint Sybesma
}

$\mathrm{Wu}$ and Bodomo (2009) argue against claims made in Cheng and Sybesma 1999. Gebhardt (2011) has contested their arguments related to the status of classifiers and the question whether all nouns in Chinese are mass. In this reply, we discuss some of the points $\mathrm{Wu}$ and Bodomo raise, arguing that (a) sortal classifiers are not lexical elements; (b) generic interpretation is not the same as kind interpretation; (c) demonstrative noun phrases do not have the same distribution and interpretation as definite noun phrases in Mandarin and Cantonese; and (d) the DP structure that $\mathrm{Wu}$ and Bodomo propose runs into serious problems with phrasal possessors. Finally, we discuss an alternative approach to the structure of the nominal domain in Chinese languages.

Keywords: classifiers, DP, Chinese

Wu and Bodomo (W\&B) (2009) argue against the claim allegedly made in Cheng and Sybesma (C\&S) 1999 that classifiers are determiners. ${ }^{1}$ In this contribution to the discussion, we argue point by point why W\&B's arguments against C\&S 1999 do not stand up to scrutiny. ${ }^{2}$ After a brief summary of the main points of C\&S 1999, we discuss the status of classifiers and a number of issues related to the interpretation of noun phrases in Mandarin and Cantonese. In the final section, after pointing out some problems with the structure of DP proposed by W\&B, we discuss an alternative approach.

\section{Summary of the Main Points of C\&S 1999}

C\&S 1999 constitutes an attempt to understand the distribution and interpretational variability of bare nouns and $[\mathrm{Cl}($ assifier $)+\mathrm{N}$ (oun)] phrases in Sinitic, taking Cantonese and Mandarin, and the variation they display, as the empirical starting point. The attempt was made against the background of theoretical discussions on the structure of the noun phrase in languages of the world more generally, in which "D'" played (and still plays) an important role (Stowell 1989, Longobardi 1994, Szabolcsi 1994). As Sinitic languages have no determiners, they lack an obvious candidate for D-ship. Still, the languages in this family feature noun phrases with, for example, definite reference: in Mandarin these are bare Ns and in Cantonese they are [Cl-N] phrases, both of which, however, can also be interpreted as indefinite. Both the variation among the different languages and the variability in interpretation of one and the same surface form made the attempt to understand what is going on all the more challenging. Another part of the background was

We thank the reviewers for their comments, questions, and suggestions. We also thank Jenny Doetjes for discussing many issues with us.

${ }^{1}$ In fact, we do not really make this claim; see footnotes 5 and 20.

${ }^{2}$ We will only address the more serious misunderstandings. 
formed by the discussion on questions relating to the basic denotation of nouns in Sinitic languages (Maybe they are all mass nouns? Or kind-referring?), and the function of classifiers in relation to this (Chierchia 1995, 1998). Aside from the just-mentioned works by Chierchia, and works such as Paris 1981, 1989 and Tang 1990, not much theoretical research had been done on these issues in 1999.

As to the mass/count question, in C\&S 1999 we made the point (following Croft (1994); more on this below) that the sortal classifiers that are used with nouns in Chinese languages when counting (among other contexts) are elements that do not create a unit, which is what measure expressions (kilo, bottle of) do; instead, they merely name the unit that is already part of the semantic denotation of the noun. We reasoned that if a noun has individual units in its semantic denotation, it should be considered a count noun. This way, cooccurrence with a sortal classifier is a diagnostic for count-noun-hood. ${ }^{3}$

With respect to distribution and interpretation, we proposed two structures, one for all indefinite noun phrases (1a) (p. 529, (39)) and one for all definites (1b) (p. 529, (40)) (in both Cantonese and Mandarin).

(1) a. Indefinite: [NumeP $\left.\left.\mathrm{Nume}^{0}\left[\mathrm{ClP}^{0} \mathrm{Cl}^{0} \mathrm{NP}^{0}\right]\right]\right]$

b. Definite: $\quad\left[\mathrm{ClP}^{0} \mathrm{Cl}^{0}\left[\mathrm{NP} \mathrm{N}^{0}\right]\right]$

Thus, definite bare nouns in Mandarin have the structure in (1b), as do definite [Cl-N] phrases in Cantonese. Similarly, all indefinites-bare Ns, [Cl-N] phrases, and [Numeral-Cl-N] phrases alike-will have the underlying structure in (1a). What seems to be happening here, we said, is that the Numeral Phrase (NumeP) layer in (1a) has the effect of undoing the definiteness of the CIP. The Numeral (Nume) head can be, but does not have to be, overtly filled.

In C\&S 1999, we argued that the definiteness is taken care of differently in the two languages. Following Chierchia (1998), we took there to be two ways to implement the necessary operation to get a definite interpretation: overtly and covertly (a last resort option, according to Chierchia). English uses its definite article the to realize this, and we proposed that Cantonese uses the classifier. In Mandarin, the use of the classifier is blocked, as a result of which this language must resort to the covert option, which involves insertion of the so-called iota operator. To lexically support this operator, N-to-Cl movement takes place. As a result, in both languages the $\mathrm{Cl}^{\circ}$ position is filled in definite noun phrases: in Cantonese by the classifier, in Mandarin by the head noun.

The use of the classifier is blocked in Mandarin for reasons we did not understand when writing C\&S $1999,{ }^{4}$ but we did point at the generalization that in Mandarin the classifier and the numeral always go together. And since the numeral is associated with indefiniteness, the classifier is not available for the role it plays in marking definiteness in Cantonese.

\footnotetext{
${ }^{3}$ For another diagnostic, also mentioned in C\&S 1999, see Cheng and Sybesma 1998. For discussion of these diagnostics, see Tang 2005 and Li 2011. For more on the question of mass and count in Chinese languages, see Cheng, Doetjes, and Sybesma 2008 and Li, Dunham, and Carey 2009, among others.

${ }^{4}$ Sybesma (2007) presents a detailed comparison of the use of the classifier in Mandarin and Cantonese and concludes that classifiers in Mandarin are only used in counting. It is the numeral, and not the noun, that requires the presence of the classifier, as a result of which the one is basically never seen without the other.
} 
In sum, in C\&S 1999 we developed analyses to account for the variability in interpretation of identical surface forms and for the variation between Cantonese and Mandarin.

\section{Sortal and Mensural Classifiers, Functional and Lexical Elements}

W\&B state that C\&S 1999 and subsequent work of ours offer arguments for the claim that classifiers are determiners, and the whole purpose of W\&B 2009 is to show that classifiers and definite articles are not the same. ${ }^{5}$

W\&B claim that classifiers cannot possibly be determiners because classifiers are contentful morphemes, while determiners are functional elements (p. 488). ${ }^{6}$ To show that classifiers have semantic content, they give the following Mandarin examples (their (1) and (2); tones added), noting that different classifiers create "different cognitive effects" (p. 488) when used with one and the same noun.

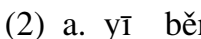

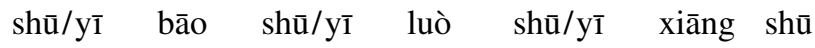
one CL:volume book/one CL:bag book/one CL:pile book/one CL:box book 'a book/a bag of books/a pile of books/a box of books'

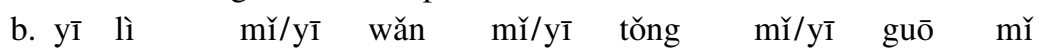
one CL:grain rice/one CL:bowl rice/one CL:barrel rice/one CL:wok rice 'a grain of rice/a bowl of rice/a barrel of rice/a wok of rice'

As Gebhardt (2011) points out, W\&B do not take into account the relevance of the important difference between sortal and mensural classifiers, a difference that is well-established (Lyons 1977, Croft 1994) and to which a whole section is devoted in C\&S 1999 (section 2.1.1). ${ }^{7}$ Mensural classifiers, also called "measure expressions," include basic measures such as kilo, as well as container measures such as $a$ box of and $a$ handful of. These are very common in languages of the world. They are contentful, because they create, or provide, arbitrary measures for masses and pluralities of countable things. Since "a boxful" is a different measure from " a pile," which

${ }^{5}$ W\&B (p. 487) quote C\&S 1999:522 as saying, “[B]oth [Mandarin and Cantonese] have the equivalent of a definite article, namely, classifiers," and the title of their article is "Classifiers $\neq$ Determiners." First, we must acknowledge that $D$, determiner, and definite article are not three different terms for the same thing. " $\mathrm{D}$ " is the head of DP, which can, but does not have to, be filled by a "determiner," and "definite articles", belong to the category of determiners. And since $\mathrm{D}^{0}$ can also be occupied by other elements, not everything found in $\mathrm{D}^{0}$ is a determiner or a definite article. This means that saying that "Cls are equivalent to a definite article" does not automatically lead to the claim that " $\mathrm{Cl}$ = D," and vice versa. This point is glossed over by W\&B. Furthermore, the quotation is taken out of context. In C\&S 1999 , it is preceded by a passage discussing the use of the iota operator as a last resort operation to determine definiteness (see section 1 above). Following a quotation from Chierchia 1998:360, which says that if a language has "a determiner $\mathrm{D}$ whose meaning is a particular type shifting, then use of [the covert iota] operation as an automatic type-changing functor is blocked,', the text of C\&S 1999 continues as follows (p. 522): "Neither Cantonese nor Mandarin has a definite article. However, both languages have the equivalent of a definite article, namely, classifiers" — which must obviously be read as 'these two languages also have an element that can be put to use to perform different functions generally associated with D/determiners'. In that sense, (definite) determiners and classifiers are "equivalent."

${ }^{6}$ Incidentally, what W\&B say about determiners is also not correct: "[D]efinite articles are devoid of semantic content and solely contribute definite status to their associated noun', (p. 488). For instance, in view of the fact that in some languages (e.g., German), number, gender, and Case are expressed and/or reflected on the definite article, clearly they may do much more.

${ }^{7}$ In their footnote $1, W \& B$ simply state that they follow the Chinese tradition in not distinguishing between the two, without explaining why the traditional Chinese view is more insightful. 
is in turn different from " a bagful,", all being different from reference to singular or simple plural instantiations, there are bound to be different "cognitive effects" depending on whether a speaker uses one or the other. A sortal classifier like běn in (2), however, "does not contribute semantic content to the expression," as Gebhardt (2011:127) phrases it.

As discussed in C\&S 1999 (see above), with reference to Croft 1994, sortal classifiers do not create a measure, as mensural classifiers do; instead, they simply name the unit that is already present in the semantic denotation of the noun. Their use is grammatically necessary. Consequently (without semantic contribution, with grammatical function), they are functional elements, just as determiners are functional elements. There is a "lexical" aspect to the sortals as well, as not all nouns combine with the same sortal; there are collocational restrictions. But this does not mean that sortal classifiers contribute meaning to the phrase as a whole. In fact, sortals offer very little room to play around with. Zhang (2007) gives a number of examples where the use of a different classifier with one and the same noun leads to highlighting a different aspect of the noun (a sheep as just an animal or a sheep as a domestic animal); but examples like these are rare, and even in such cases the choice of classifier is limited to a small preestablished set. One cannot use the classifier for animals in referring to the pursuers of one's daughter, for instance. In short, that "meaningfulness can be said to be one of the defining properties of classifiers" (W\&B 2009: 488) is simply not true.

W\&B further claim that, in contrast to definite articles, "classifiers in Chinese constitute an open word class"' (p. 490). They refer to Zhang 2007:50 for this, but Zhang explicitly says that "weight units and mass noun classifiers [Zhang's term for measure words; see Zhang 2007:45] are extrinsic to the head noun and belong to an open-ended class.' Zhang says nothing about sortal classifiers. ${ }^{8}$ The examples that $\mathrm{W} \& \mathrm{~B}$ give suggest the same thing: the open-endedness is limited to the nonsortal classifiers. In fact, as functional elements, sortals are often regarded as closed-class elements (e.g., Barner, Inagaki, and Li 2009), just like determiners. ${ }^{9}$ Zhang does point out that some sortals can also be used as nonsortals (see also Erbaugh 2006). The element tiáo, for instance, is a sortal for yú 'fish', shé 'snake', and shéngzi 'rope' and can arguably be regarded as a nonsortal in (3). The fact that some elements play a dual role does not make the class of sortals an open class.

(3) Mandarin

sān tiáo zhǐ

three slip paper

'three slips of paper'

Another argument for why sortal classifiers should be looked upon as grammatical elements that are required for grammatical reasons rather than for content can be deduced from their use by children and aphasics. When subjects (children and aphasics) are aware that a classifier is obligatory in a certain position in the sentence but do not know which is the appropriate one to use,

\footnotetext{
${ }^{8}$ Zhang (2007) does refer to the classifier system as an "open system,', without implying that sortal classifiers form an "open class" in the morphological sense; see Zhang 2007:57.

${ }^{9}$ Erbaugh (2006:40) says that sortals belong to an open class, but on page 42 she states that there are "about 75 ", of them, which does not seem to indicate an open class.
} 
they use another one (often the general one). This means that they make a collocational (or lexical) mistake rather than a grammatical one (Erbaugh 1986, Ahrens 1994).

In short, contrary to the claim in W\&B 2009, there are many good reasons for taking sortal classifiers to be primarily functional rather than lexical/contentful elements. ${ }^{10}$

\section{Form and Interpretation}

W\&B make a number of statements regarding the interpretation of nominal phrases in Mandarin and Cantonese. Some of them are incorrect, while others present too simple a picture. We will discuss a number of these cases here.

First, in C\&S 1999 we emphasize the individualizing function of sortal classifiers. In particular, the presence of classifiers yields singularities, as a result of which, we claim, they are incompatible with kind denotation. W\&B state that our claim is "easily falsified" by data "where an indefinite singular NP of the form $[y i-\mathrm{Cl}-\mathrm{N}]$ is interpreted universally" (p. 492); these data are given here (W\&B's (5), tones added).

\section{(4) Mandarin}

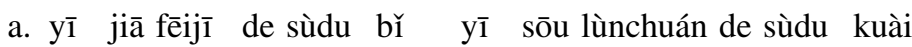
one CL plane 's speed COMP one CL ship 's speed fast 'An airplane's speed is faster than a ship's.'

b. ȳî̀ ge zhànshì yào suíshí zhǔnbèi wèi guó xīshēng zìjǐ one CL soldier should anytime prepare for country sacrifice self

'A soldier should prepare to sacrifice himself anytime for his country.'

c. ȳ̄ wèi hăo lăoshī bù jǐnjǐn jiāo xuéshēng zěnme xuéxí one CL good teacher not just teach student how study

'A good teacher doesn't just teach students how to study.'

Aside from the fact that "kind denoting" and "having universal quantification" are not quite the same thing, we would like to point out that this is the wrong characterization of these sentences, in any event. These are sentences that Krifka et al. (1995) and many others call "characterizing sentences," which are different from sentences with a universal quantification. The core problem here is that $\mathrm{W} \& \mathrm{~B}$ do not consider the distinction between generic readings that come about through the binding of an indefinite noun phrase by a generic operator, and kind-referring noun phrases without such a generic operator. A clear-cut test, as indicated in Krifka et al. 1995, is the use of kind predicates, which favor a kind-referring interpretation, as indicated in (5) (examples from Krifka et al. 1995:10).

\footnotetext{
${ }^{10} \mathrm{~W} \& \mathrm{~B}$ discuss whether or not all Chinese nouns are mass, and what role the classifier plays. Gebhardt (2011:128) notes that "W\&B's assumptions about the mass/count denotations of nouns are unclear" and that they "misread" the claims in this domain in C\&S 1999 as well as "mischaracterize" a number of points made in Borer 2005. There is no need, then, to go into what W\&B say about the mass/count question. We simply want to point out one thing, which can easily lead to misunderstandings regarding the referentiality of nouns in Mandarin. W\&B approvingly cite other works (Denny 1986:298, cited in Aikhenvald 2000:318) as saying that in Chinese, "[t]he noun refers to some kind of mass and the classifier gives a unit of this mass"' (p. 488). The empirical problem with this kind of statement is that in Mandarin, though not in Cantonese, the noun does not need an overt classifier to refer to individual units, as is clear from the fact that bare nouns can have definite reference.
} 
(5) a. The lion will become extinct soon.

b. Lions will become extinct soon.

c. *A lion will become extinct soon. (nontaxonomic reading)

d. Bronze was invented as early as $3000 \mathrm{BC}$.

Only kinds can die out or be invented. In English, as the data in (5) show, definite noun phrases and bare plurals can be used with kind predicates, while an indefinite noun phrase such as a lion cannot, even though an indefinite noun can obtain a generic reading under other circumstances (see Krifka et al. 1995). Now, consider sentences in Mandarin and Cantonese with kind predicates. Compare the Mandarin bare noun cases in $(6 \mathrm{a}, \mathrm{c})$ with the [yi-Cl-N] cases in $(6 \mathrm{~b}, \mathrm{~d})$, and the Cantonese bare noun cases in $(7 \mathrm{a}, \mathrm{c})$ with the $[$ jat-Cl-N] cases in $(7 \mathrm{~b}, \mathrm{~d})$.

(6) Mandarin

a. shīzi hěn kuài jiù huì juézhǒng lion very quick then will be.extinct 'Lions will be extinct very soon.'

b. *ȳ̄ tóu shīzi hěn kuài jiù huì juézhǒng one CL lion very quick then will be.extinct

'*A lion will be extinct very soon.'

c. fēijī shì Wright-xiōngdì fāmíng-de airplane be Wright-brothers invent-DE

'Airplanes were invented by the Wright brothers.'

d. *ȳ̄ jiā fēij̄i shì Wright-xiōngdì fāmíng-de one CL airplane be Wright-brothers invent-DE '*An airplane was invented by the Wright brothers.'

(7) Cantonese

a. $\mathrm{si}^{1} \mathrm{zi}^{2}$ hou $^{2}$ faai $^{3} \mathrm{zau}^{6}$ wui $^{5} \mathrm{zyut}^{6} \mathrm{zung}^{2}$

lion very quick then will be.extinct

'Lions will be extinct very soon.'

b. *jat ${ }^{1} \mathrm{zek}^{3} \mathrm{si}^{1} \mathrm{zi}^{2}$ hou $^{2}$ faai $^{3} \mathrm{zau}^{6}$ wui $^{5} \mathrm{zyut}^{6} \mathrm{zung}^{2}$

one $\mathrm{CL}$ lion very quick then will be.extinct

'*A lion will be extinct very soon.'

c. fei ${ }^{1}$ gei $^{1}$ hai $^{6}$ Wright-hing ${ }^{1}$ dai $^{6}$ fat $^{3}$ ming $^{4}-$ ge $^{3}$

airplane be Wright-brothers invent-GE

'Airplanes were invented by the Wright brothers.'

d. $*_{\text {jat }}{ }^{1}$ ga $^{3}$ fei $^{1}$ gei $^{1}$ hai $^{6}$ Wright-hing ${ }^{1}$ dai $^{6}$ fat $^{3}$ ming $^{4}-$ ge $^{3}$

one CL airplane be Wright-brothers invent-GE

'*An airplane was invented by the Wright brothers.'

From $(6 a, c)$ and $(7 a, c)$ it is clear that in both Mandarin and Cantonese, bare nouns can be used with kind predicates; in other words, bare nouns can be used as kind-referring noun phrases. In contrast, $(6 \mathrm{~b}, \mathrm{~d})$ and $(7 \mathrm{~b}, \mathrm{~d})$ show that indefinite noun phrases with the form ['one'-Cl-N] cannot be used with kind predicates. As indicated in C\&S 1999, this is due to the fact that the presence 
of the classifier yields individuality, which results in a reading that is not compatible with a kind predicate. $^{11}$

This is not a surprising result, since crosslinguistically, indefinite NPs are not considered as kind-referring, as Krifka et al. (1995) clearly show. The generic interpretation that arises in (4a-c) and $(8 \mathrm{a}-\mathrm{c})$ (from Krifka et al. 1995:12, 18, 17) is probably due to the nature of the sentences: these qualify as characterizing sentences.

(8) a. An Italian drinks wine with his dinner.

b. A lion (usually) weighs more than $200 \mathrm{lbs}$.

c. Lions are mammals.

The interpretation of these sentences can be accounted for by positing a generic operator, which binds the indefinite noun phrase. Example (4c) (repeated here as (9a)) can thus have the interpretation represented roughly in $(9 b)$.

(9) Mandarin

a. ȳ̄ wèi hăo lăoshī bù jǐnjǐn jiāo xuéshēng zěnme xuéxí one CL good teacher not just teach student how study

'A good teacher doesn't just teach students how to study.'

b. GEN [x; y] (x is a teacher \& y are students; if $\mathrm{x}$ is good, $\mathrm{x}$ does not just teach y how to study)

The sentence is interpreted as 'in general, if a teacher is good, he or she does not just teach students how to study'. It is not a universal interpretation, as W\&B claim, but a generic one.

Second, W\&B raise two objections against claims made in C\&S 1999 concerning Cantonese classifiers. The first objection has to do with the "variable interpretation" of Cantonese classifiers, the second with the role played by context in determining a definite interpretation of Cantonese $[\mathrm{Cl}-\mathrm{N}]$ phrases. We look at these objections now.

With regard to the "variable interpretation," compare (10a) and (10b), the former a typical case showing a definite reading of $[\mathrm{Cl}-\mathrm{N}]$ phrases in Cantonese, the latter an existential sentence with an indefinite. Example (10a) is originally (19a) in C\&S 1999; (10b) is provided by W\&B (their (11)) (both given here with tones).

(10) Cantonese

a. gaa $^{3} \mathrm{ce}^{1} \mathrm{zo}^{2}-\mathrm{zyu}^{6} \quad \mathrm{go}^{3} \operatorname{ceot}^{1} \mathrm{hau}^{2}$

CL car block-CONT CL exit

'The car is blocking the exit.'

b. $\mathrm{jau}^{5}\left(\mathrm{jat}^{1}\right) \mathrm{gaa}^{3} \mathrm{ce}^{1} \mathrm{zo}^{2}-\mathrm{zyu}^{6} \quad \mathrm{go}^{3} \operatorname{ceot}^{1} \mathrm{hau}^{2}$

have (one) CL car block-CONT CL exit

'There is a car blocking the exit.'

\footnotetext{
${ }^{11}$ The marking of individuality is not incompatible with the occurrence of numerals higher than 1 , if numerals are multipliers rather than counters.
} 
While acknowledging that $[\mathrm{Cl}-\mathrm{N}]$ phrases can be definite in Cantonese, W\&B claim that "the definite interpretation of a classifier phrase is contextually constrained" (p. 495). ${ }^{12}$ They go on to explain that (10a) is appropriate only in a context in which some car has already become the topic of conversation, and both speaker and hearer know the referent of the noun in question. " 'Otherwise, a word like jau 'exist, have' would have to be used before the classifier phrase", (p. 496). To illustrate, they give the existential sentence in (10b).

This is quite puzzling. If the interpretation of a phrase is wholly determined by the (pragmatic) context, why is $j a u^{5}$ 'exist, have' needed to make the phrase indefinite? One of the points of C\&S 1999 was to explain why one surface string ([Cl-N] in the case of Cantonese, bare nouns for Mandarin) can have a definite as well as an indefinite interpretation. In section 3.2.2 of C\&S 1999, the account offered is the one given in (1) above: "surface strings of the form $[\mathrm{Cl}+\mathrm{N}]$ have two different structural representations" (p. 529); in the case of an indefinite interpretation, $[\mathrm{Cl}-\mathrm{N}]$ is actually a NumeP, while a definite interpretation corresponds to a ClP (i.e., a ClassifierP). This account may not be correct, but it is a structural account. Replacing this account with an "'account', which says that definite phrases are definite and can only be used in contexts in which a phrase with definite reference is appropriate and indefinite ones are indefinite and can only be used in contexts in which a phrase with indefinite reference is called for does not seem to lead to greater insight.

Also, the "constraint" that W\&B describe is the classic "familiarity theory of definiteness" (see Heim 1983), and the information status of definite noun phrases has led to active discussion also in relation to definite noun phrases in English, showing that Chinese in fact is not unique in this respect.

Equally problematic is $\mathrm{W} \& \mathrm{~B}$ 's claim that $[\mathrm{Cl}-\mathrm{N}]$ and $[\mathrm{Dem}-\mathrm{Cl}-\mathrm{N}]$ in Cantonese are interchangeable. While acknowledging that in English, a phrase with the is different from a phrase with a demonstrative, W\&B explicitly say that in Chinese, a phrase with a demonstrative "invariably gives rise to a definite reading', (p. 498, and elsewhere). However, in Mandarin and Cantonese the closest counterparts of a phrase with the in English are a bare noun and a [Cl-N] phrase, respectively. In a context in which a book and a journal are on the table and someone says, "The book is mine," the Mandarin rendering is (11a), with the bare noun, rather than (11b), with a demonstrative and a classifier. ${ }^{13}$ In Cantonese, (12a), with [Cl-N], is preferred over (12b). (For discussion, see Sybesma and Sio 2008.)

\section{(11) Mandarin}

a. shū shì wǒ-de

book be $1 \mathrm{SG}-\mathrm{DE}$

'The book/The books is/are mine.'

\footnotetext{
${ }^{12}$ It should be noted that $\mathrm{W} \& \mathrm{~B}$ obscure the discussion by adding parenthesized demonstratives to the [Cl-N] phrases in some of the sentences taken from C\&S 1999, like the one given here in (10a). By doing this, they suggest that [Cl$\mathrm{N}]$ phrases and [Dem-Cl-N] phrases are more or less the same, which is not the case (see below). As a consequence, their description on pages 495-496 of the context in which a [Cl-N] phrase is used felicitously is incorrect.

${ }^{13}$ Interestingly, another possibility is [Dem-N]: nà shü shì wǒ-de 'that book coP lsG-DE'- that is, with a demonstrative, but without a classifier.
} 
b. nèi/zhèi běn shū shì wǒ-de that/this CL book be 1SG-DE

'That/This book is mine.'

(12) Cantonese

a. bun ${ }^{2} \mathrm{syu}^{1}$ hai $^{6} \mathrm{ngo}^{5}-\mathrm{ge}^{3}$

CL book be 1SG-GE

'The book is mine.'

b. $\mathrm{li}^{1} / \mathrm{go}^{2}$ bun ${ }^{2} \mathrm{syu}^{1}$ hai $^{6} \mathrm{ngo}^{5}-\mathrm{ge}^{3}$

that/this CL book be $1 \mathrm{SG}-\mathrm{GE}$

'That/This book is mine.'

In other words, when W\&B say (p. 494) that "[f] or a bare [Cl-N] phrase in Mandarin to have the same interpretation as a $[$ the-N] phrase in English, . . it must combine with a demonstrative plus the numeral $y i$ 'one',', they make a statement that is empirically incorrect (in any case, it is incomplete), as deletion of the $\mathrm{Cl}$ would be the preferred option (as in (11a)). Similarly, as mentioned in footnote 12, adding demonstratives to some of the examples from C\&S 1999 gives the impression that it makes no difference whether they are there or not, but this is not the case. ${ }^{14}$ That the examples with and without the demonstratives are not the same is also clear when we look at sentences such as the one in (13a), involving definite predicates. We see that in this case, demonstratives must be used in Cantonese (in contrast with the English counterpart in (13b)), showing that [Dem-Cl-N] and [Cl-N] are not interchangeable. ((13) is taken from Cheng, Heycock, and Zamparelli 2010, which offers a possible account for the fact that $[\mathrm{Cl}-\mathrm{N}]$ is not felicitous as a definite predicate.)

(13) Context: We have been talking about pupils who will be chosen to meet the prime minister. I have explained that exactly two pupils will be chosen: one boy and one girl.

a. Cantonese

John hai ${ }^{6} *\left(\mathrm{go}^{2}\right) \mathrm{go}^{3}$ naam $^{4} \mathrm{zai}^{2}$

John COP DEM CL boy

'John is that boy.'

b. John is the boy.

Another test, helpfully suggested by a reviewer, is to see whether demonstratives and classifiers in Cantonese behave the same in [X boy is tall and X boy is not tall]. In English, if $\mathrm{X}$ is a demonstrative, the sentence does not necessarily lead to a contradiction (i.e., That boy is tall and that boy is not tall), while if $\mathrm{X}=$ the, a necessary contradiction results. In Cantonese, using a demonstrative does not lead to a contradiction, while using [Cl-N] does.

\footnotetext{
${ }^{14}$ W\&B's examples taken from news broadcasts do not clarify much, as it is well-known that this is a register very different from colloquial speech.
} 
(14) Cantonese
a. go $^{2}$ go $^{3}$ naam $^{4}$ zai $^{2}$ hou $^{2}$ gou $^{1} ;$ go $^{2}$ go $^{3}$ naam $^{4}$ zai $^{2} \mathrm{~m}^{4}$ gou $^{1}$ that $\mathrm{CL}$ boy very tall that $\mathrm{CL}$ boy not tall
b. \#go ${ }^{3}$ naam $^{4}$ zai $^{2}$ hou $^{2}$ gou $^{1} ;$ go $^{3}$ naam $^{4} \mathrm{zai}^{2} \mathrm{~m}^{4}$ gou $^{1}$
$\mathrm{CL}$ boy very tall $\mathrm{CL}$ boy not tall

In short, it is incorrect to give the demonstrative in Chinese the same status as the definite determiner in English; and it is incorrect to equate [Cl-N] with [Dem-Cl-N] in Cantonese.

\section{The Structure of DP}

\subsection{Wu and Bodomo's Proposal}

$\mathrm{W} \& \mathrm{~B}$ offer the structures in (15) to account for the definite interpretation of [Cl-N]s in Cantonese (their (16), tones added).

(15) a.

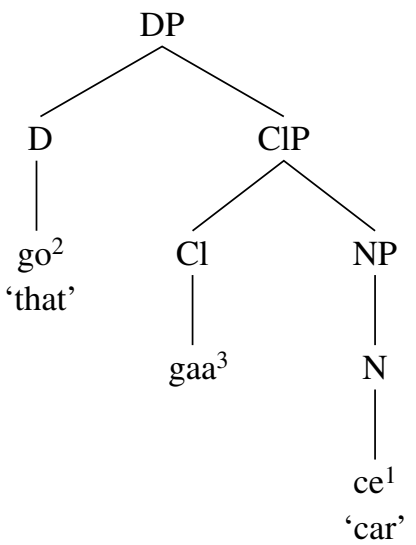

b.

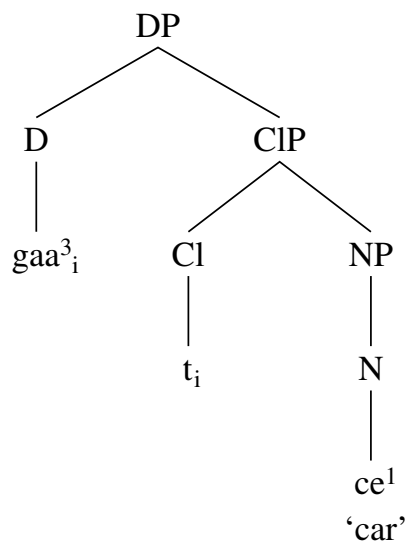

W\&B state that "classifiers, while unable to indicate definiteness by themselves, may be associated with the deictic function by moving to D and being combined with it" (p. 499).

We would like to make two comments here. First, this proposal comes as a surprise in light of the previous sections of W\&B 2009, as it is very much in the spirit of C\&S 1999 in the sense that the classifier plays a prominent role in expressing referentiality/definiteness (and W\&B make it clear that they see classifiers as contentful, lexical elements, which cannot possibly have anything to do with such a grammatical function).

Second, W\&B do not define what they mean by deictic, but since in (15a) the $\mathrm{D}^{0}$ position is occupied by a demonstrative, we assume that they mean demonstrativity, which means that their analysis implies that $[\mathrm{Cl}-\mathrm{N}]$ phrases are identical to phrases with a demonstrative, which they are not, as we have just shown.

Next, W\&B consider that their proposed structure has an additional advantage in view of noun phrases with a possessor. Cantonese possessives can take the form $\left[\mathrm{NP}_{1}-\mathrm{Cl}-\mathrm{NP}_{2}\right]$, and $\mathrm{W} \& \mathrm{~B}$ accommodate the possessor in the $\mathrm{D}^{0}$ position (see their structure (18), p. 500). However, the possessor can take a phrasal form, as shown here in $(16 a-b)$. This being the case, the advantage 
turns into a disadvantage, since phrases like $g o^{2}-g o^{3} h o k^{6} s a a n g^{1}$ 'that student' or $g o^{2}-g o^{3} n a a m^{4}$ $z^{2} i^{2}$ 'that boy' can also appear as "bare possessors" (i.e., possessors not accompanied by the modification marker $g e^{3}$ ), and as phrases, they cannot occupy the $\mathrm{D}^{0}$ position. $^{15}$

(16) Cantonese
a. $\left[\mathrm{go}^{2} \mathrm{go}^{3}\right.$ hok $^{6}$ saang $\left.^{1}\right]$ bun $^{2}$ syu $^{1}$
that CL student $\quad \mathrm{CL}$ book
'that student's book'
b. $\left[\mathrm{go}^{2} \mathrm{go}^{3}\right.$ naam $\left.^{4} \mathrm{zai}^{2}\right] \mathrm{deoi}^{3}$ ngaan $^{5}$ geng $^{2}$
that $\mathrm{CL}$ boy $\quad \mathrm{CL}^{\text {pair }}$ glasses
'that boy's glasses'

Another problem associated with the structures in (15) is that "bare possessors" can also appear above a demonstrative, as illustrated in (17a-b).

\section{(17) Cantonese}
a. $\mathrm{keoi}^{5} \mathrm{go}^{2} \mathrm{bun}^{2} \mathrm{syu}^{1}$
he that $\mathrm{CL}$ book
'that book of his'
b. $\mathrm{Wu}^{4} \mathrm{fei}^{1} \mathrm{go}^{2}$ bun $^{2} \mathrm{syu}^{1}$
'that book of Wufei's'
Wufei that CL book

These cases show that the bare possessor cannot possibly be in the position that hosts the demonstrative, since the demonstrative is present. This shows that W\&B's idea of putting bare possessors in $\mathrm{D}^{0}$ is incorrect.

Finally (and crucially in view of C\&S 1999's comparative point of departure), it is not clear how Mandarin fits into this structure, as bare nouns can be definite in Mandarin. W\&B are silent about this point.

\subsection{D or No D?}

A proposal very similar to W\&B's had already been put forth by Simpson (2005). Simpson's proposal is based on an extensive crosslinguistic discussion about the expression of definiteness in relation to the occurrence of bare classifiers. The discussion involves languages like Vietnamese, Hmong, and Nung, which are similar to Cantonese in that noun phrases with bare classifiers can indicate definiteness. Simpson assumes a structure that is headed by $\mathrm{D}^{0}$, suggesting that when the $\mathrm{D}$ projection is occupied (by having something in $\mathrm{D}^{0}$ or in Spec,DP), its interpretation is definite. More specifically, if demonstratives are in Spec,DP, or if $\mathrm{Cl}^{0}$ moves to $\mathrm{D}^{0}$, a definite interpretation results. ${ }^{16}$ Crucially, Simpson states that when the numeral is present, it blocks $\mathrm{Cl}^{0}$

\footnotetext{
15 They may occupy the specifier position of $\mathrm{D}$, as a reviewer suggests, but that is not what W\&B propose.

${ }^{16}$ See Simpson 2005, as well as Sybesma and Sio 2008 and articles cited therein, for detailed discussion of demonstratives as XPs (and not as a $\mathrm{D}^{0}$ ).
} 
from moving to $\mathrm{D}^{0}$, resulting in an indefinite interpretation. As far as we can tell, Simpson does not assume that Nume ${ }^{0}$ moves to $\mathrm{D}^{0}$ to trigger an indefinite reading, from which we can conclude that $\mathrm{D}^{0}$ is inherently definite. In Simpson's proposal, the definite and indefinite interpretations will thus have the following representations:

(18) a. Indefinite: $\left.\left[\mathrm{DP} \mathrm{D}^{0}\left[\mathrm{NumeP} \mathrm{Nume}^{0}\left[\mathrm{ClP}^{0} \mathrm{Cl}^{0} \mathrm{NP}^{0}\right]\right]\right]\right]$

b. Definite: $\left.\quad\left[\mathrm{DP} \mathrm{D}^{0}\left[\mathrm{ClP}^{0} \mathrm{Cl}_{\mathrm{NP}} \mathrm{N}^{0}\right]\right]\right]$

These representations are quite similar to the ones in C\&S 1999, given in (1). In Simpson's analysis, both structures are topped by a D projection, which is absent in (1). But note that in both analyses, the NumeP is crucial in determining indefiniteness, leading to an inactive D projection in Simpson's case. The only difference, really, is the place where definiteness is encoded. In Simpson's approach, it is associated exclusively with $\mathrm{D}^{0}$; in the approach taken in C\&S 1999 , it is associated with $\mathrm{Cl}^{0}$.

Independent of the position of the demonstratives, Sio (2006) argues that there is evidence for an additional functional layer on top of NumeP or CIP (see also Sybesma and Sio 2008). In Cantonese, a possessor marked with subordinative marker $g e^{3}$ can appear above the [Dem-Cl$\mathrm{NP}]$ sequence, or above NP, but not above [Cl-NP].

(19) Cantonese
a. zoeng $^{3}$ saam $^{1} \mathrm{ge}^{3}$ laang $^{1}$ saam $^{1}$
Zoeng Saam GE sweater
'Zoeng Saam's sweater(s)'
b. *zoeng ${ }^{3}$ saam $^{1}$ ge $^{3}$ gin $^{6}$ laang $^{1}$ saam $^{1}$
Zoeng Saam GE CL sweater
Intended: 'Zoeng Saam's sweater'
c. zoeng $^{3}$ saam $^{1}$ ge $^{3}$ go $^{2}$ gin $^{6}$ laang $^{1}$ saam $^{1}$
Zoeng Saam GE that CL sweater
'that sweater of Zoeng Saam's'
$(=(15 a-c)$ in Sybesma and Sio 2008)

Assuming that the possessor marked with $g e^{3}$ is an adjoined phrase, if demonstratives are simply in Spec,ClP, it would be unclear why (19b) is ungrammatical while (19c) is grammatical. Sio thus argues that there is an additional functional projection above the NumeP, which she calls SpecificityP (SP), to which the possessor is adjoined. ${ }^{17}$ This is the analysis Sio (2006) proposes:

(20) a. Indefinite: $\left.\left.\left[\mathrm{SP}^{0} \mathrm{~S}_{\text {NumeP }} \mathrm{Nume}^{0}\left[\mathrm{ClP}^{0} \mathrm{Cl}^{0}{ }_{\mathrm{NP}} \mathrm{N}^{0}\right]\right]\right]\right]$

b. Definite: $\quad\left[\mathrm{SP} \mathrm{S}^{0}\left[\mathrm{ClP} \mathrm{Cl}^{0}\left[{ }_{\mathrm{NP}} \mathrm{N}^{0}\right]\right]\right]$

Ignoring the labeling, Simpson's (2005) analysis and Sio's (2006) can both be represented as in (21).

\footnotetext{
${ }^{17}$ See Sio 2006 and Sybesma and Sio 2008 for details and for further evidence provided by Wenzhou.
} 
(21) a. Indefinite: $\left.\left[\mathrm{FP} \mathrm{F}^{0}\left[\mathrm{NumeP} \mathrm{Nume}^{0}\left[\mathrm{ClP}^{0} \mathrm{Cl}^{0} \mathrm{NP}^{0}\right]\right]\right]\right]$

b. Definite: $\quad\left[\mathrm{FP} \mathrm{F}^{0}\left[\mathrm{ClP}^{0}{ }^{0}\left[\mathrm{NP} \mathrm{N}^{0}\right]\right]\right]$

However, the role Sio has in mind for the top FP ("SpecificityP") is very different from the one assigned to it in Simpson's analysis ("DP'). Sio's proposal goes back to the role of the higher D in Hungarian proposed by Szabolcsi (1994). Szabolcsi posits two D-type projections in the noun phrase, mainly because two D-type elements can cooccur in Hungarian. The first one, heading the topmost functional projection in the phrase, is the article; it is either $a(z)$ 'the' or $\emptyset$ 'a, some', and Szabolcsi labels it 'D.' The second one is realized by any of a list of quantificational elements such as minden 'every', kevés 'few', and semelyik 'neither' or the demonstratives elemelezen 'this', ama/azon 'that'. This second type of D is labeled 'Det', by Szabolcsi. Szabolcsi argues that D is a "subordinator," just like C: both "enable the clause and the noun phrase to act as arguments"' (p. 214, (80b)). D mainly has a grammatical function. On the other hand, DetP determines the quantification and the definiteness of the noun phrase. The form realized by the D head (definite/strong $a(z)$ or indefinite/weak $\emptyset$ ) is determined by a "concord-like process" (i.e., agreement) with DetP.

Returning to Mandarin and Cantonese, the question that arises is whether the FP in (21) above the NumeP or CIP encodes (in)definiteness (as in Simpson 2005 and W\&B 2009) or reflects the (in)definiteness already determined elsewhere in the phrase. The latter is what Sio opts for, following Szabolcsi. More specifically, Sio argues that $\mathrm{F}^{0}$ in FP (SpecificityP) agrees with either Nume ${ }^{0}[-$ def $]$ or $\mathrm{Cl}^{0}\left[+\right.$ def] for [ \pm definiteness]. In particular, the $\mathrm{F}^{0}$ has an uninterpretable [def] feature, which it can check off upon agreeing with an interpretable [ \pm def] feature (with Nume ${ }^{0}$ having a $[-$ def $]$ value while $\mathrm{Cl}^{0}$ has a $[+$ def $]$ value).

In short, although the representations in (18) and (20) seem like notational variants of each other, the topmost $\mathrm{F}^{0}$ is exclusively associated with definiteness in the former, while it is not in the latter, which merely reflects the (in)definiteness already present elsewhere in the phrase. ${ }^{18}$

So, does Chinese have a D? Bošković (2008, 2009, 2010) proposes that determinerless languages in which bare nouns may have both definite and indefinite readings do not have a D projection. How about Chinese, then?

In C\&S 1999:513, we distinguish three functions D may have. One is the function we just discussed, which is based on claims by Szabolcsi (1987, 1994:181) (see also Stowell 1989): D turns NPs, which are predicates (or propositions), into arguments; Szabolcsi takes it that in this respect typical Ds like articles are similar to complementizers, and both are "subordinators.", Second, D has an individualizing or singularizing function (Longobardi 1994:634): it has the ability to pick out a single instance of whatever is described by the predicative NP (see also

${ }^{18}$ A reviewer points out that the analysis in C\&S 1999 is rather cumbersome when it comes to the (in)definite interpretation: the definiteness of the classifier is undone by the indefiniteness of a numeral, and if there is a demonstrative present, it will then switch the interpretation back to (some kind of) definiteness. Kayne (2008:311) points out that in French, des, which is arguably the indefinite plural article, involves the same process, since des is a contraction of de and the definite article les. 
Higginbotham 1985). This function we took in C\&S 1999 to be connected to the third function (similar, yet not identical) that can be performed by $\mathrm{D}$, that of mediating between the description (predication) provided by the NP and whatever specific entity in the real world the description is applied to. We referred to this function (possibly a discourse function), as the deictic function of D. ${ }^{19}$

This last function seems to point to a general characteristic of language (C\&S 1999:518): for example, the same kind of division of labor exists in the verbal domain between the describing VP and the referring, deictic T, which links the event described in the VP to a particular event associated with a particular point on the time axis. This division of labor may very well be a property of Universal Grammar: some (lexical) entities describe, whereas other entities perform the deictic discourse function of linking the description to some particular object or event in the real world. In languages with articles/determiners, the deictic function in the nominal phrase is taken care of by the article/determiner. However, this should not lead one to conclude that if a language has no articles/determiners, no element performs the deictic function. If the describing/ referring dichotomy is indeed part of Universal Grammar, then if a language has no articles/ determiners, some other element in the language must perform the deictic function. In C\&S 1999, we suggest that in Chinese $\mathrm{Cl}^{0}$ performs some of the functions performed by $\mathrm{D}^{0}$, including the deictic function (as defined here). ${ }^{20}$

The question is what is gained by postulating a DP. In view of the fact that there is no empirical reason for it (Chinese languages have no articles), does it make sense to just postulate an empty D for the sake of universality? This is what W\&B do (p. 499). They state that since it is generally assumed that arguments are DPs, it must be the case that a $[\mathrm{Cl}-\mathrm{N}]$ phrase when functioning as an argument is a DP. We would like to raise the question: what is it about D that makes a DP have this function, and is this (whatever it is) necessarily and exclusively associated with D?

The literature on DP shows that the superstructure of the NP contains a number of functions, some of which are involved in relating the NP to the context (turning NPs into arguments as well as the deictic function discussed above). We also notice that typical D elements, such as articles and determiners, hardly ever do just one thing: they may be involved in the expression of number (French singular le vs. plural les), in classification (French masculine le vs. feminine la), and in definiteness (French definite le vs. indefinite $u n$ ). Is French le primarily a determiner that also performs the other functions, or is it primarily a gender classifier, performing other functions as well? And if the former option is the correct one, does this mean that elements performing these different functions at the same time must necessarily and primarily be determiners? Of course,

${ }^{19}$ W\&B 2009 is partly devoted to discussing whether classifiers have a "deictic function" or not. We will not go into the points W\&B raise, because in evaluating whether classifiers are deictic, they use a different definition of this term than the one given in C\&S 1999.

${ }^{20}$ In C\&S 1999, we associated $\mathrm{Cl}$ with $\mathrm{D} /$ determiner in the sense that $\mathrm{Cl}$ performs functions that are performed by typical D elements in other languages. This is explicitly stated on pages 520, 534, and 538. 
we can look for a determiner in Chinese, but we can also simply acknowledge the fact that the classifier, at least in Cantonese, similarly performs several functions at the same time.

Ultimately, it may all be a matter of definition and terminology. One could simply decide that the topmost layer in the nominal phrase is called "DP' — by definition, just as the outer layer of the sentence is always "CP' - without any strong claims as to what it shall do; going by the analysis in (21), Cl will never occupy the head of this DP, in which case $\mathrm{Cl}$ is not a D. Alternatively, we can attach the label " $D$ ' to whatever element is the deictic/referring head, in which case C\&S 1999 may be interpreted as saying that $\mathrm{Cl}^{0}=\mathrm{D}^{0}$ (which, we maintain, is not the same as saying that $\mathrm{Cl}=$ determiner; see footnote 5).

\section{References}

Ahrens, Kathleen. 1994. Classifier production in normals and aphasics. Journal of Chinese Linguistics 22: 202-246.

Aikhenvald, Alexandra. 2000. Classifiers: A typology of noun categorization devices. Oxford: Oxford University Press.

Barner, David, Shunji Inagaki, and Peggy Li. 2009. Language, thought, and real nouns. Cognition 111: 329-344.

Borer, Hagit. 2005. In name only. Oxford: Oxford University Press.

Bošković, Željko. 2008. What will you have, DP or NP? In NELS 37, ed. by Emily Elfner and Martin Walkow, 101-114. Amherst: University of Massachusetts, Graduate Linguistic Student Association.

Bošković, Željko. 2009. The NP/DP analysis and Slovenian. In Proceedings of the University of Novi Sad Workshop on Generative Syntax 1, 53-73. Novi Sad: Filozofski fakultet u Novom Sadu.

Bošković, Željko. 2010. On NPs and clauses. Ms., University of Connecticut, Storrs.

Cheng, Lisa Lai-Shen, Jenny Doetjes, and Rint Sybesma. 2008. How universal is the Universal Grinder? Linguistics in the Netherlands 2008:50-62.

Cheng, Lisa Lai-Shen, Caroline Heycock, and Roberto Zamparelli. 2010. Definitely predicative? Paper presented at the Network Final Conference "Bantu, Chinese, Romance Nouns and Noun Phrases." Leiden University, October 2010.

Cheng, Lisa Lai-Shen, and Rint Sybesma. 1998. Yi-wan tang, yi-ge tang: Classifiers and massifiers. TsingHua Journal of Chinese Studies, new series, 28:385-412.

Cheng, Lisa Lai-Shen, and Rint Sybesma. 1999. Bare and not-so-bare nouns and the structure of NP. Linguistic Inquiry 30:509-542.

Chierchia, Gennaro. 1995. Plurality of mass nouns and the notion of "semantic parameter." In Events and grammar, ed. by Susan Rothstein, 53-103. Dordrecht: Kluwer.

Chierchia, Gennaro. 1998. Reference to kinds across languages. Natural Language Semantics 6:339-405.

Croft, William. 1994. Semantic universals in classifier systems. Word 45:145-171.

Denny, J. Peter. 1986. The semantic role of noun classifiers. In Noun classes and categorization: Proceedings of a symposium on categorization and noun categorization, Eugene, Oregon, 1983, ed. by Colette Craig, 297-308. Amsterdam: John Benjamins.

Erbaugh, Mary S. 1986. Taking stock: The development of Chinese noun classifiers historically and in young children. In Noun classes and categorization, ed. by Colette Craig, 399-436. Amsterdam: John Benjamins.

Erbaugh, Mary S. 2006. Chinese classifiers: Their use and acquisition. In The handbook of East Asian psycholinguistics. Vol. 1, Chinese, ed. by Ping Li, Li Hai Tan, Elizabeth Bates, and Ovid Tzeng, 39-51. Cambridge: Cambridge University Press.

Gebhardt, Lewis. 2011. Classifiers are functional. Linguistic Inquiry 42:125-130. 
Heim, Irene. 1983. File change semantics and the familiarity theory of definiteness. In Meaning, use and the interpretation of language, ed. by Rainer Bäuerle, Christoph Schwarze, and Arnim von Stechow, 164-190. Berlin: Walter de Gruyter.

Higginbotham, James. 1985. On semantics. Linguistic Inquiry 16:547-593.

Kayne, Richard S. 2008. Comparative remarks on French and Italian definite articles. In Foundational issues in linguistic theory: Essays in honor of Jean-Roger Vergnaud, ed. by Robert Freidin, Carlos P. Otero, and Maria Luisa Zubizarreta, 291-321. Cambridge, MA: MIT Press.

Krifka, Manfred, Francis Jeffry Pelletier, Gregory N. Carlson, Alice ter Meulen, Gennaro Chierchia, and Godehard Link. 1995. Genericity: An introduction. In The generic book, ed. by Gregory N. Carlson and Francis Jeffry Pelletier, 1-124. Chicago: University of Chicago Press.

Li, Peggy, Yarrow Dunham, and Susan Carey. 2009. Of substance: The nature of language effects on entity construal. Cognitive Psychology 58:487-524.

Li, Xu-Ping. 2011. On the semantics of classifiers in Chinese. Doctoral dissertation, Bar-Ilan University.

Longobardi, Giuseppe. 1994. Reference and proper names. Linguistic Inquiry 25:609-665.

Lyons, John. 1977. Semantics. Cambridge: Cambridge University Press.

Paris, Marie-Claude. 1981. Problèmes de syntaxe et de sémantique en linguistique chinoise [Problems of syntax and semantics in Chinese linguistics]. Paris: Collège de France.

Paris, Marie-Claude. 1989. Linguistique générale et linguistique chinoise: Quelques exemples d'argumentation [General linguistics and Chinese linguistics: Some examples of argumentation]. Paris: Université Paris 7, UFRL.

Simpson, Andrew. 2005. Classifiers and DP structure in Southeast Asia. In Handbook of comparative syntax, ed. by Guglielmo Cinque and Richard S. Kayne, 806-838. Oxford: Oxford University Press.

Sio, Joanna U.-S. 2006. Modification and reference in the Chinese nominal. Doctoral dissertation, Leiden University.

Stowell, Tim. 1989. Subjects, specifiers, and X-bar theory. In Alternative conceptions of phrase structure, ed. by Mark R. Baltin and Anthony S. Kroch, 232-262. Chicago: University of Chicago Press.

Sybesma, Rint. 2007. Běifāng fāngyán hé Yuèyǔ zhōng míngcí de kěshǔbiāojì [Markers of countability on the noun in Mandarin and Cantonese]. Yǔyánxué Lùncóng 35:234-245.

Sybesma, Rint, and Joanna U.-S. Sio. 2008. D is for demonstrative: Investigating the position of the demonstrative in Chinese and Zhuang. In "Syntactic Categories and Their Interpretation in Chinese," ed. by Huba Bartos, special issue, The Linguistic Review 25(3-4):453-478.

Szabolcsi, Anna. 1987. Functional categories in the noun phrase. In Approaches to Hungarian 2, ed. by István Kenesei, 167-190. Szeged: JATE.

Szabolcsi, Anna. 1994. The noun phrase. In The syntactic structure of Hungarian, ed. by Ferenc Kiefer and Katalin É. Kiss, 179-274. San Diego, CA: Academic Press.

Tang, Chih-Chen Jane. 1990. Chinese phrase structure and the extended X'-theory. Doctoral dissertation, Cornell University, Ithaca, NY.

Tang, Chih-Chen Jane. 2005. Nouns or classifiers: A non-movement analysis of classifiers in Chinese. Language and Linguistics 6:431-472.

$\mathrm{Wu}$, Yicheng, and Adams Bodomo. 2009. Classifiers $\neq$ determiners. Linguistic Inquiry 40:487-503.

Zhang, Hong. 2007. Numeral classifiers in Mandarin Chinese. Journal of East Asian Linguistics 16:43-59.

(Cheng)

Department of Linguistics

Leiden University

P.O. Box 9515

2300 RA, Leiden

The Netherlands

L.L.Cheng@hum.leidenuniv.nl 
(Sybesma)

Department of Chinese Studies

Leiden University

P.O. Box 9515

2300 RA, Leiden

The Netherlands

R.P.E.Sybesma@hum.leidenuniv.nl

\section{Flavors of Division}

\section{Éric Mathieu}

The theoretical aim of this article is to integrate the singulative into the theory of division proposed by Borer (2005) and other theoretical linguists (e.g., Krifka 1995, Doetjes 1996, 1997, Chierchia 1998, Cheng and Sybesma 1999). To illustrate my claim, I offer a brief case study of Ojibwe, an Algonquian language, which I argue uses gender shift (from inanimate to animate) to mark singulativization. Singulatives, as morphological markers, are primarily known from Celtic, Afro-Asiatic, and Nilo-Saharan languages, but are not a known feature of Algonquian languages. Further support for my claim that the grammar of Algonquian languages embeds a singulative system comes from Fox (Mesquakie).

Keywords: singulative, division, number, gender, Algonquian, Celtic, plural, classifiers

Borer (2005) proposes that all nouns in all languages are in need of being portioned out before they can interact with the count system. In Chinese, this is achieved by (count) classifiers for count nouns and (mass) classifiers for mass nouns (Cheng and Sybesma 1999). ${ }^{1}$ In English, plural marking takes the role of classifiers for count nouns, and measure phrases are used in lieu of

First, and foremost, thank you to Philomene Chegahno, Berdina Johnston, Donald Keeshig, Joanne Keeshig, Isabel Millette, Juanita Pheasant, Ernestine Proulx, and Ella Waukey for sharing their beautiful language with me. Special thanks to Joanne Keeshig for introducing me to the members of the community and to Sheila Keeshig for introducing me to the teachers of the Chippewas of Nawash Elementary School. Many thanks also to Shirley Williams from Trent University. Miigwech! Second, for their comments and chats about the topic of this article, thanks to Michael Barrie, Hagit Borer, Rose-Marie Déchaine, Bethany Lochbihler, Richard Rhodes, Elizabeth Ritter, and Martina Wiltschko. Finally, many thanks to the reviewers. Funding by SSHRC is gratefully acknowledged: grants 230424-120699-2001 and 230611-1206992001.

${ }^{1}$ Following Cheng and Sybesma (1999), classifiers can roughly be divided into two groups: classifiers that create a unit of measure, and those that simply name the unit in which the entity denoted by the noun naturally occurs. Cheng and Sybesma refer to the classifiers that create a unit of measure as massifiers (short for mass-classifiers) and to the ones that simply name the unit of natural semantic partitioning as classifiers (short for count-classifiers). 